\title{
Article \\ Experimental Investigation into the Seismic Performance of Prefabricated Reinforced Masonry Shear Walls with Vertical Joint Connections
}

\author{
Zhiming Zhang ${ }^{1}$ and Fenglai Wang ${ }^{2,3, * \mathbb{D}}$ \\ 1 School of Civil Engineering, Harbin Institute of Technology, Harbin 150090, China; \\ zhangzhiming724@hotmail.com \\ 2 Key Lab of Structures Dynamic Behavior and Control of the Ministry of Education, Harbin Institute of \\ Technology, Harbin 150090, China \\ 3 Key Lab Smart Prevention and Mitigation of Civil Engineering Disasters of the Ministry of Industry and \\ Information Technology, Harbin Institute of Technology, Harbin 150090, China \\ * Correspondence: fl-wang@hit.edu.cn; Tel.: +86-139-3616-8890
}

check for updates

Citation: Zhang, Z.; Wang, F.

Experimental Investigation into the Seismic Performance of Prefabricated Reinforced Masonry Shear Walls with Vertical Joint Connections. Appl. Sci. 2021, 11, 4421. https://doi.org/ 10.3390/app11104421

Academic Editor: Sang Whan Han

Received: 23 April 2021

Accepted: 12 May 2021

Published: 13 May 2021

Publisher's Note: MDPI stays neutral with regard to jurisdictional claims in published maps and institutional affiliations.

Copyright: (c) 2021 by the authors. Licensee MDPI, Basel, Switzerland. This article is an open access article distributed under the terms and conditions of the Creative Commons Attribution (CC BY) license (https:/ / creativecommons.org/licenses/by/ $4.0 /)$.
Abstract: In this study, four single-story reinforced masonry shear walls (RMSWs) (two prefabricated and two cast-in-place) under reversed cyclic loading were tested to evaluate their seismic performance. The aim of the study was to evaluate the shear behavior of RMSWs with flanges at the wall ends as well as the effect of construction method. The test results showed that all specimens had a similar failure mode with diagonal cracking. However, the crack distribution was strongly influenced by the construction method. The lateral capacity of the prefabricated walls was $12 \%$ and $27 \%$ higher than that of the corresponding cast-in-place walls with respect to the rectangular and T-shaped cross sections. The prefabricated walls showed better post-cracking performance than did the cast-in-place wall. The secant stiffness of all the walls decreased rapidly to approximately $63 \%$ of the initial stiffness when the first major diagonal crack was observed. The idealized equivalent elastic-plastic system showed that the prefabricated walls had a greater displacement ductility of 3.2-4.8 than that of the cast-in-place walls with a displacement ductility value of 2.3-2.7. This proved that the vertical joints in prefabricated RMSWs enhanced the seismic performance of walls in shear capacity and ductility. In addition, the equivalent viscous damping of the specimens ranged from 0.13 to 0.26 for prefabricated and cast-in-place walls, respectively.

Keywords: prefabricated reinforced masonry shear wall; cyclic loading; vertical joint; seismic performance

\section{Introduction}

Reinforced masonry shear walls (RMSWs) have been widely used in medium-height or high-rise buildings in low-seismicity regions in North America and China because of their high lateral strength, stiffness, ductility, and energy dissipation [1-3]. With the rapid development of the building industry, prefabricate RMSWs structures are adopted because of the advantages of high component quality, quick onsite construction, energy savings, reduced labor consumption, and environmental benefits compared with the traditional cast-in-place construction method. Prefabricated RMSWs are the main horizontal bearing components to resist lateral forces transferred from concrete slabs, which act as rigid diagrams during earthquakes. Therefore, for the past few decades many researchers have focused on the in-plane seismic behavior of RMSWs and the connection method between prefabricated walls.

Two distinct in-plane failure modes of RMSWs are flexural failure and shear failure [4,5]. Numerous experimental investigations have been carried out in recent decades. The results have demonstrated that the flexural failure can be well-defined and characterized by the tensile yielding of vertical reinforcement and compressive crushing at the toes 
of the walls. The lateral capacity can be precisely predicted based on the plane cross-section assumption [6-9]. Furthermore, the shear failure is characterized by the diagonal cracks with a brittle behavior, which represents a low energy dissipation capacity [10-13]. Due to the complexity of each component contributing to the lateral strength, there are some experimental programs concentrating on the design modes of RMSWs failing in the shear wall under reversed cyclic loading [14-16]. In addition, a few studies were carried out using artificial neural networks to predict the lateral capacity of reinforced masonry walls [17-19]. The results showed that the proposed models perform better than do existing equations. However, the models based on the artificial neural networks lack the mechanics theory and their accuracy depends on the experimental database.

Regarding the prefabricated RMSWs, the key problem is the connection of prefabricated members. Two main connection joints are horizontal joints and vertical joints in the shear wall structures. The crucial part of the horizontal joints is the connection of vertical reinforcement. Xu et al. $[20,21]$ tested nine prefabricated RMSWs with horizontal joints to evaluate the seismic performance under lateral cyclic loading. The results show that prefabricated RMSWs have higher lateral capacity than do traditional walls. The paper explained that prefabricated RMSWs eliminate the cleaning-hole blocks at the bottom course of the wall because of the change of construction technique. This improvement changes the connection method of vertical reinforcement from overlapped to continuous. The continuous vertical rebar performs better than an overlapped one does as a shear wall component. With respect to the vertical joints in the prefabricated RMSWs, Zhang et al. [22] proposed an innovative vertical joint connection of prefabricated RMSWs [22]. The research variables were axial compressive stress, horizontal reinforcement ratio, and construction methods. The results show the proposed vertical joints enhanced the seismic performance of prefabricated RMSWs in shear capacity and ductility.

In addition, a few studies focused on the seismic performance of RMSWs with flanges or boundary conditions to enhance the ductility and energy dissipation [23-26]. Shedid et al. $[24,25]$ tested seven RMSWs with different end configurations and aspect ratios under cyclic loading. The results showed that the ductility values of the walls that were flanged and end-confined were, respectively, 1.5 and 2 times those of their rectangular counterparts. To maintain the same lateral capacity, more than $40 \%$ in the amount of vertical reinforcement was saved by using the proposed methods. Omar et al. [26] tested six RMSWs with different end configurations. The test results showed that the displacement ductility value of the rectangular, flanged wall and the wall with boundary elements with low reinforcement ratios were almost similar. However, with higher reinforcement ratios, the attained displacement ductility value for the walls that had flanges or boundary elements were $33 \%$ and $40 \%$ higher than that of their counterparts, respectively. However, few studies were conducted on the seismic behavior of prefabricated RMSWs with flanges and vertical joints connections in prefabricated RMSWs, which are considered to be one of the most crucial parts of the reinforced masonry shear wall structural system.

To clarify and address this issue, an experimental study on the prefabricated RMSWs with flanges was conducted to evaluate the seismic performance. Four full-scale fully grouted RMSWs were designed under the Chinese code [27] and tested under reversed cyclic loading. The aim of the study was to evaluate the shear behavior of RMSWs with flanges at the wall ends as well as the effect of construction method on seismic performance. The experimental program and test results are summarized in this paper. The crack patterns, failure modes, and force-displacement responses were obtained. The influence of flanges and construction methods on the lateral capacity, displacement ductility, stiffness degradation, energy dissipation, and equivalent viscous damping was evaluated.

\section{Materials and Methods}

\subsection{Test Specimens}

In this study, four single-story, full-scale, fully grouted RMSWs were tested to evaluate the seismic performance. Table 1 summarizes the dimensions, reinforcement details, and 
studied parameters of the specimens. The configuration details of the specimens are illustrated in Figure 1. The research parameters of this study were construction method and type of cross section. All the specimens were vertically loaded with an axial compressive stress of $1.05 \mathrm{MPa}$, which is $5 \%$ of the masonry compressive strength. The horizontal reinforcement was uniformly embedded in bond beams with a spacing of $400 \mathrm{~mm}$ along the wall height and terminated with 90 degree hooks at the ends of the walls. The horizontal reinforcement ratio of the specimens was $0.132 \%$ based on the gross area. The walls were denoted as PCMW, CMW, PCMWT, and CMWT, respectively. PCMW denoted the masonry walls constructed with a prefabricated technique and CMW denoted cast-in-place masonry walls. Compared to the rectangular cross-sectional walls (PCMW and CMW), the T-shaped section specimens (PCMWT and CMWT) had one flange at each end of the wall. The vertical joint was designed at the middle of the specimen. The reinforcement configuration at the vertical joint was comprised of four vertical reinforcement and distributed stirrups, which were designed to satisfy the requirements of strong connection and weak member according to [28]. Spiral stirrups were placed at the ends of the walls with a height of five courses, as shown in Figure 1a-d.

Table 1. Dimensions and reinforcement details of the test walls.

\begin{tabular}{|c|c|c|c|c|c|c|c|c|c|c|}
\hline \multirow{2}{*}{ Wall ID } & \multirow{2}{*}{$\underset{(\mathrm{mm})}{\mathbf{H}}$} & \multirow{2}{*}{$\mathrm{L}(\mathrm{mm})$} & \multirow{2}{*}{$\mathrm{d}(\mathrm{mm})$} & \multirow{2}{*}{$\begin{array}{c}\text { Flange } \\
(\mathrm{mm})\end{array}$} & \multicolumn{4}{|c|}{ Reinforcement Details } & \multirow{2}{*}{$\begin{array}{c}\text { Axial } \\
\text { Stress } \\
\sigma_{\mathrm{n}}(\mathrm{MPa})\end{array}$} & \multirow{2}{*}{$\begin{array}{l}\text { Construction } \\
\text { Method }\end{array}$} \\
\hline & & & & & Horizontal & $\rho_{h}(\%)$ & Vertical & $\rho_{\mathrm{v}}(\%)$ & & \\
\hline PCMW & 2790 & 2390 & 190 & - & 2C8@400 & 0.132 & $\begin{array}{c}6 \mathrm{C} 16+4 \mathrm{C} 8+ \\
4 \mathrm{C} 14\end{array}$ & 0.443 & 1.05 & Prefabricated \\
\hline CMW & 2790 & 2390 & 190 & - & 2C8@400 & 0.132 & $6 \mathrm{C} 16+6 \mathrm{C} 8$ & 0.330 & 1.05 & Cast-in-place \\
\hline PCMMT & 2790 & 2390 & 190 & 590 & 2C8@400 & 0.132 & $\begin{array}{c}6 \mathrm{C} 16+4 \mathrm{C} 8+ \\
4 \mathrm{C} 14\end{array}$ & 0.415 & 1.05 & Prefabricated \\
\hline CMWT & 2790 & 2390 & 190 & 590 & 2C8@400 & 0.132 & $8 \mathrm{C} 16+8 \mathrm{C} 8$ & 0.330 & 1.05 & Cast-in-place \\
\hline
\end{tabular}

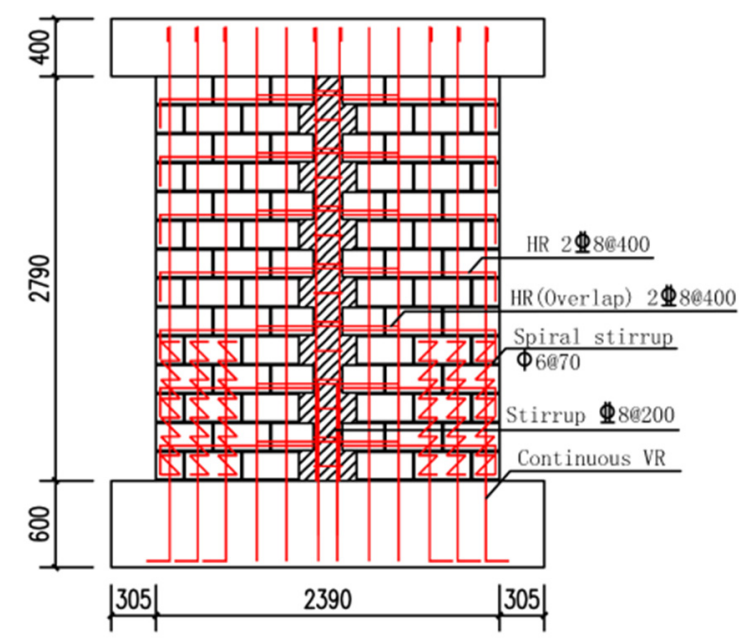

(a)

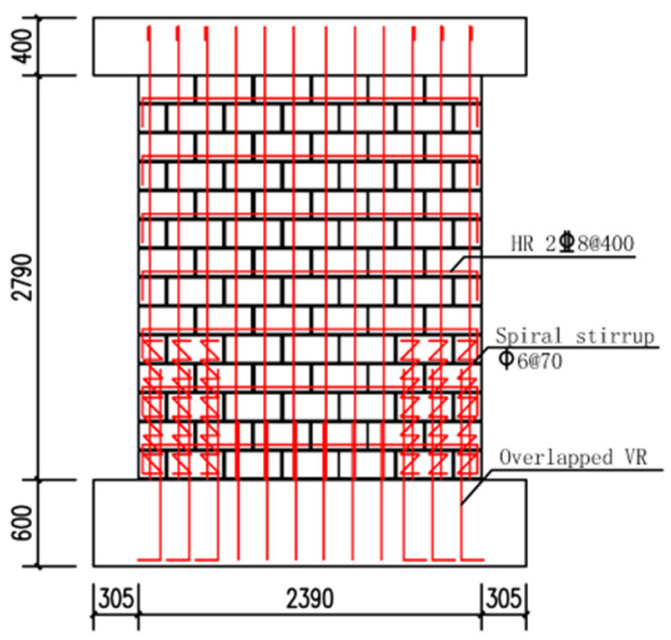

(b)

Figure 1. Cont. 


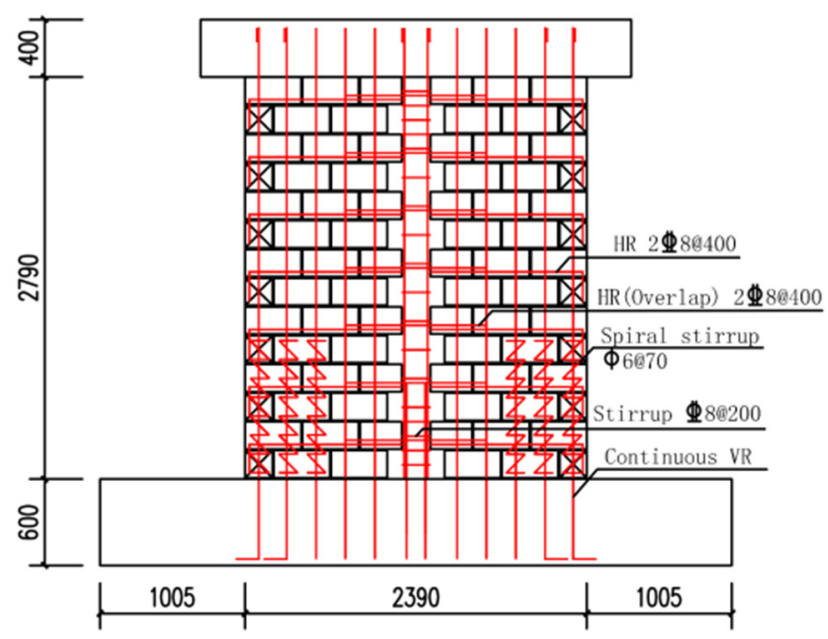

(c)

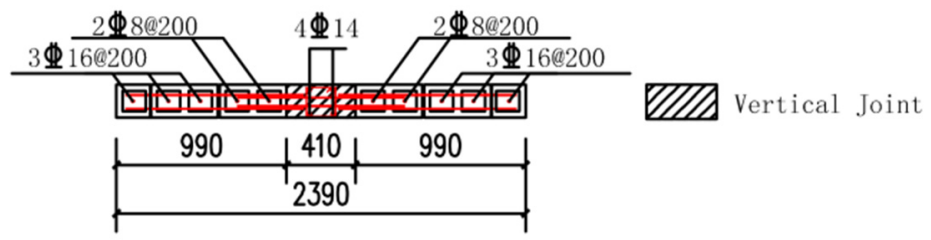

(e)

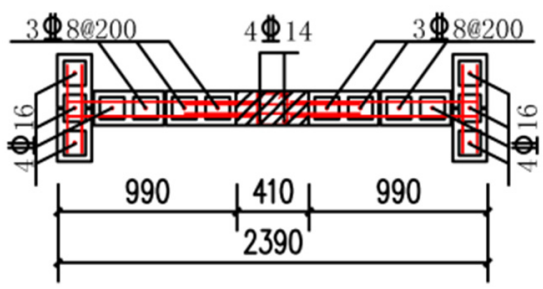

$(\mathrm{g})$

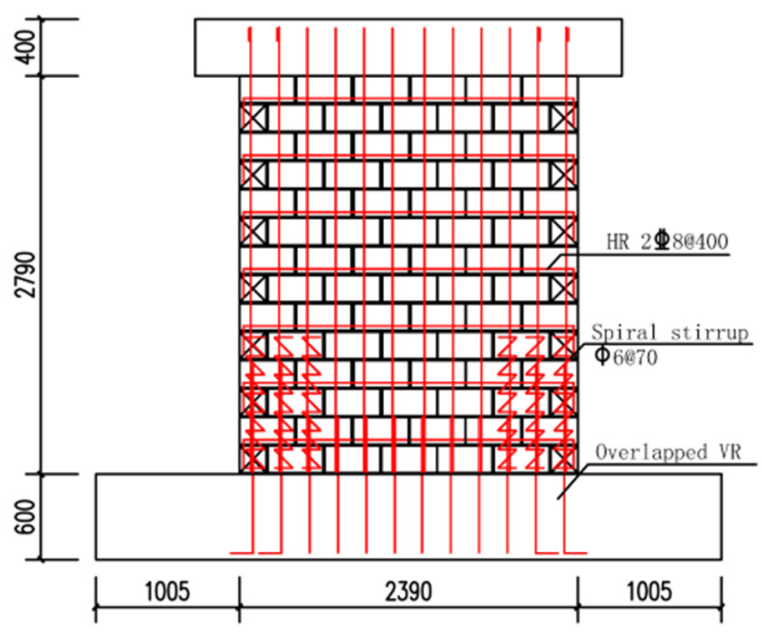

(d)

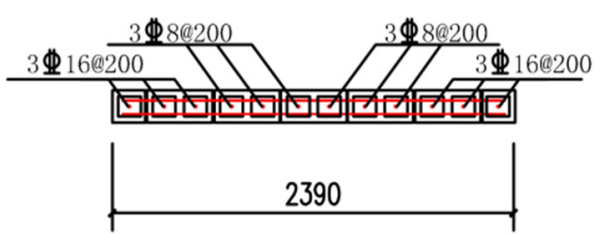

(f)

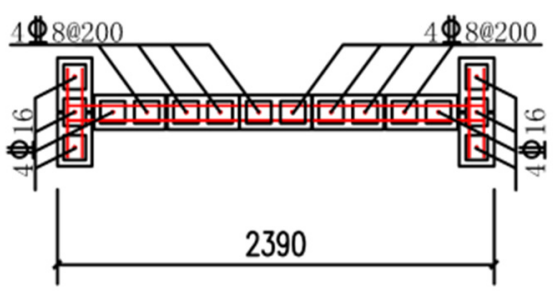

(h)

Figure 1. Configuration and reinforcement details of test specimens: (a) Front view of PCMW; (b) Front view of CMW; (c) Front view of PCMWT; (d) Front view of CMWT; (e) Reinforcement configuration of PCMW; (f) Reinforcement configuration of CMW; (g) Reinforcement configuration of PCMWT; (h) Reinforcement configuration of CMWT.

Considering the lab conditions, including the lab space, capacity of the actuator, and predicted shear-dominated failure mode, all the walls were heavily reinforced in the vertical direction with a vertical reinforcement ratio from $0.330 \%$ to $0.443 \%$. The distributed vertical reinforcement was located at the center of vertical cell. As a result, the ratio of theoretical flexural strength and shear strength based on the equation proposed by GB 50003-2011 was approximately 1.2 for the rectangular walls and 1.4 for the T-shaped walls. The vertical reinforcements were anchored to the foundation and bottom concrete beams with a sufficient length to prevent anchoring failure. 


\subsection{Specimen Construction}

All the test walls were constructed by the same experienced mason under professional supervision. The entire construction process using a prefabricated technique is divided into four steps and illustrated in Figure 2. The construction process is described as follows: (1) The foundation concrete walls with the vertical reinforcement anchors were constructed on site. In the meantime, the prefabricated walls were constructed on the yellow steel beams to allow for clean up the redundant mortar from vertical cells during the laying of the units, as shown in Figure 2a,b; (2) After the hollow units were cured to a specified strength that met the requirement of lifting, the wall segments were hoisted safely to the assigned locations and supported by steel tubes as shown in Figure 2c,d; (3) The hollow walls were grouted with pre-mixed fine concrete before installing the vertical joint reinforcement cage and templates; (4) The top reinforced concrete beam was constructed to transfer the loads from the actuators and provide the fixed boundary condition.
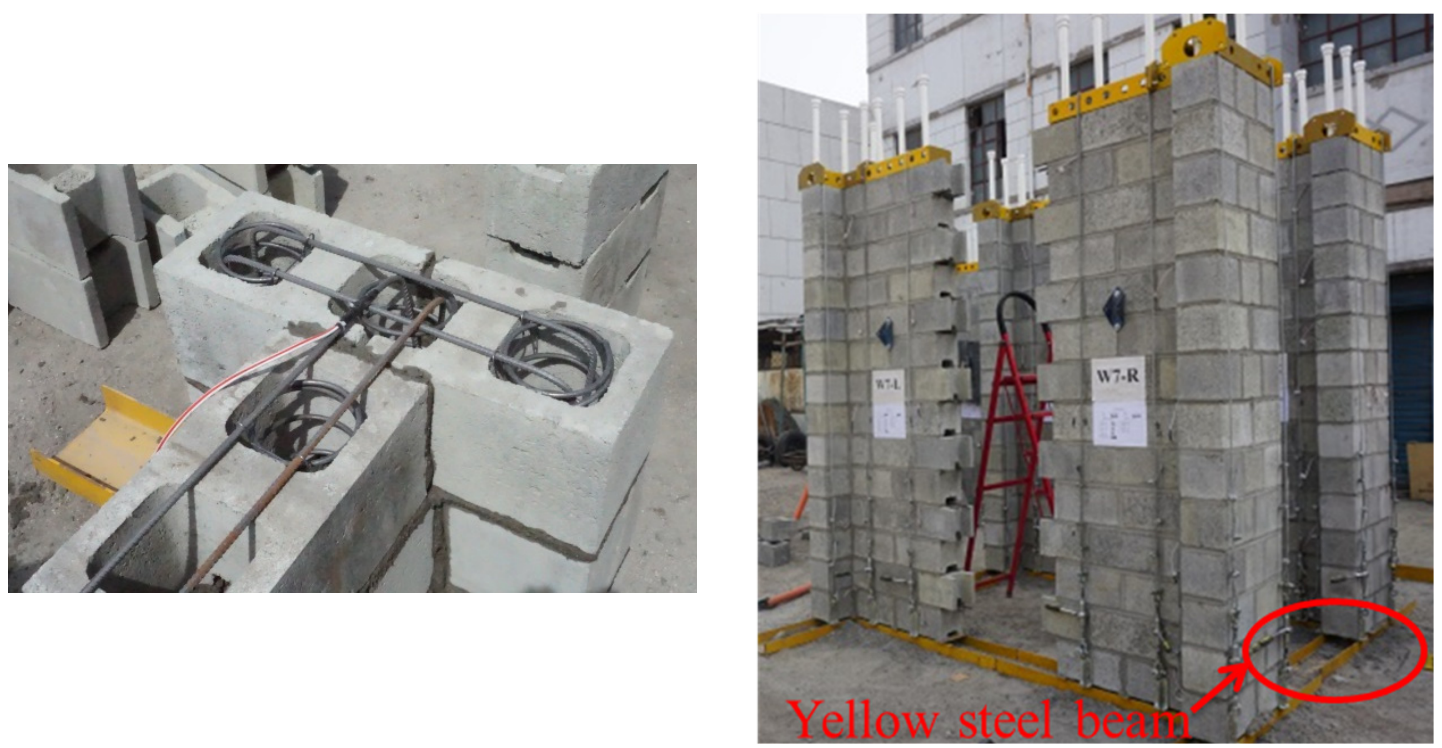

(a)

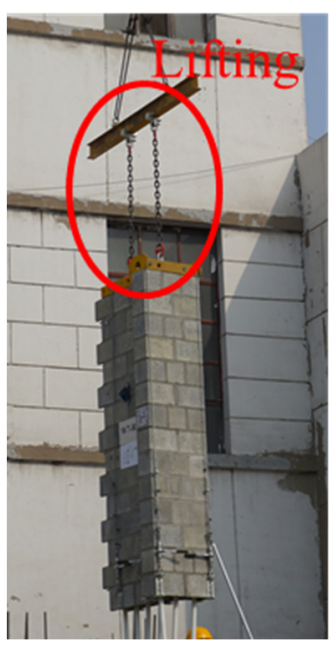

(c) (b)

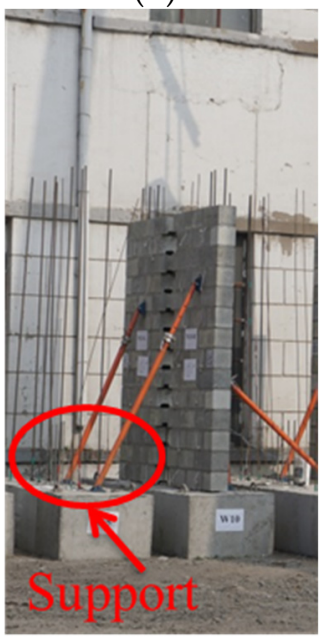

(d)

Figure 2. Construction details of test specimens with the prefabricated technique: (a) reinforcement configuration of hollow wall; (b) completion of hollow wall construction; (c) lifting of hollow wall; (d) adjustment and support of the wall. 
With respect to the cast-in-place walls, there were mainly two aspects different from the prefabricated walls. First, no vertical connection joints existed. Second, the first course units of the cast-in-place walls were cleaning holes where the vertical reinforcement overlapped.

\subsection{Material Properties}

Two main types of units were used in the test as shown in Figure 3, which were bond-beam units and cleaning-hole units, respectively. The overall dimensions of the two kinds of units were the same: $390 \mathrm{~mm}$ (length) $\times 190 \mathrm{~mm}$ (height) $\times 190 \mathrm{~mm}$ (thickness). The ratio of the vertical cell to the entire volume of the unit was $47 \%$. The face shell of the unit was $30 \mathrm{~mm}$. Bond-beam units have the advantages of grouting continuity in both the vertical and horizontal directions. The cleaning-hole units were only constructed in the first course of the cast-in-place specimens where the redundant mortar was first eliminated and then the vertical reinforcement was overlapped. The material test was conducted on the same day as the wall test.

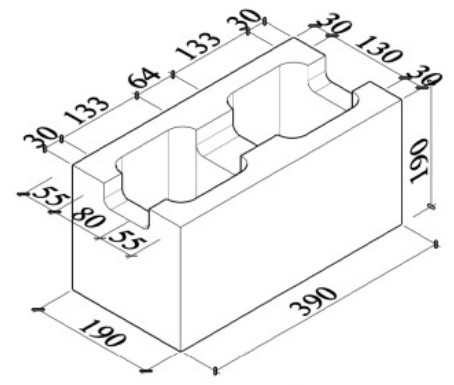

(a)

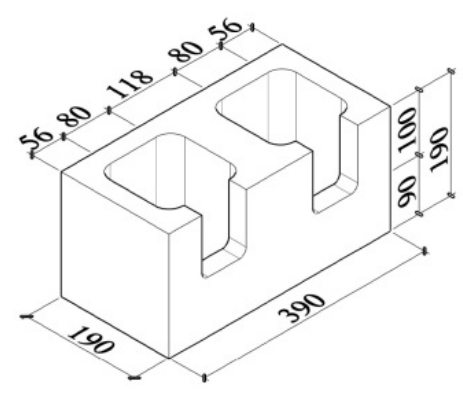

(b)

Figure 3. Dimensions of the (a) bond-beam units and (b) cleaning-hole units ( $\mathrm{mm}$ ).

The average compressive strength of the units was $17.4 \mathrm{MPa}$ (c.o.v. $=8.3 \%$ ) based on the gross area. The mortar cubes with dimensions of $70.7 \mathrm{~mm} \times 70.7 \mathrm{~mm} \times 70.7 \mathrm{~mm}$ had an average 28 -day compressive strength of $13.1 \mathrm{MPa}$ (c.o.v. $=4.8 \%$ ). The dimension of grout samples was $100 \mathrm{~mm} \times 100 \mathrm{~mm} \times 100 \mathrm{~mm}$. The premixed fine grout had a slump of $200 \pm 20 \mathrm{~mm}$ and was added with 5\% volume of expanding agent, which satisfies [29]. The average compressive stress of grout was $45.0 \mathrm{MPa}$ (c.o.v. $=4.0 \%$ ). In addition to the above-mentioned material test, the prism test was also carried out because of the material complexity of masonry. The dimension of the prism was $590 \mathrm{~mm}$ (length) $\times 990 \mathrm{~mm}$ (height) $\times 190 \mathrm{~mm}$ (thickness). The average compressive strength of the prisms was 21.0 MPa (c.o.v. $=8.2 \%$ ). All the samples were cured in the same conditions as the test walls. The average yield strength of the D8, D14, and D16 bars were $452 \mathrm{MPa}, 463 \mathrm{MPa}$, and $455 \mathrm{MPa}$, respectively. The average ultimate strength of the D8, D14, and D16 bars were $637 \mathrm{MPa}$, $652 \mathrm{MPa}$, and $612 \mathrm{MPa}$, respectively. The number of samples for each size of reinforcement was three.

\subsection{Test Setup and Instrumentation}

Figure 4 shows the test set-up of the test. The lateral reversed loads and constant vertical loads were exerted by three MTS hydraulic actuators with a capacity of $1300 \mathrm{kN}$. An L-shaped steel beam was designed to transfer the lateral and axial loads from the actuators to the test specimens. 


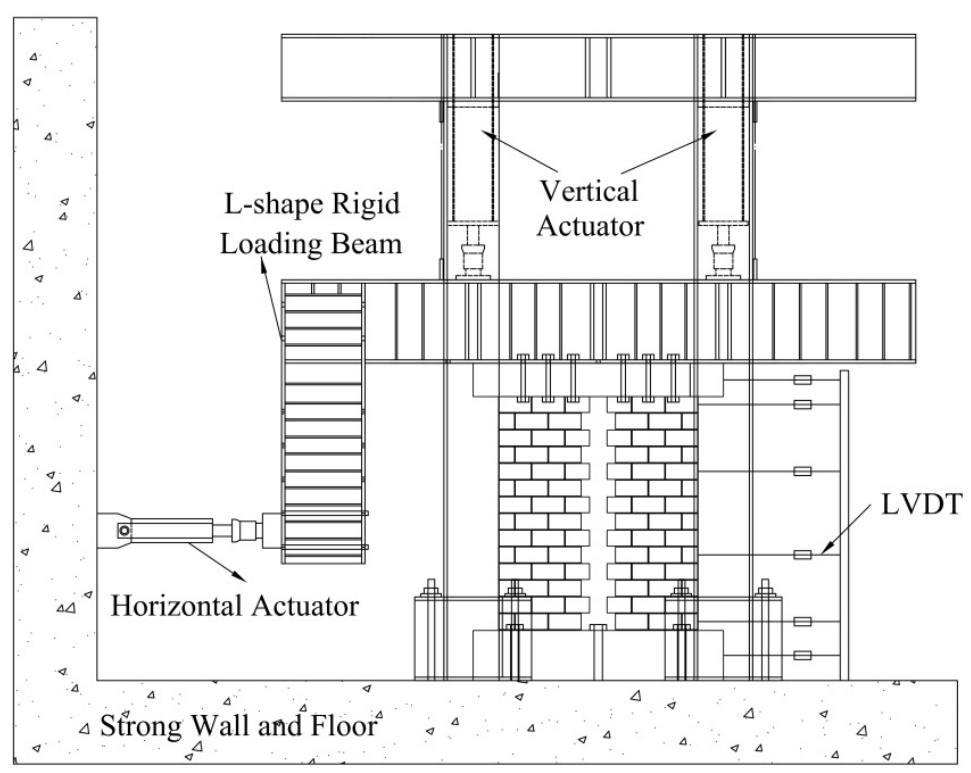

Figure 4. Test setup and instrumentation.

The L-shaped steel beam was bolted to three actuators that were anchored to the rigid reaction floor. To prevent the wall from moving out of plane, two bracing rollers were placed on each side of the specimens. During the test, the two vertical actuators were operated by assigned instruction to provide constant axial loads and constrain the rotation of the specimen. The foundation concrete beam of the specimen was anchored to the laboratory floor by six bolts to prevent slide and uplift, which was considered as a fixed boundary condition. Hence, the boundary conditions of all the specimens were fixed-fixed with a shear span-to-depth ratio of 0.58 .

As shown in Figure 2, a total of six linear variable differential transformers (LVDTs) at different heights of the wall were used to measure the lateral displacement relative to the foundation floor of the specimen. Two LVDTs were used to monitor the uplift of foundation beam. All the data including the loads from three actuators and displacements from LVDTs were recorded automatically by the acquisition system at a specified frequency.

\subsection{Loading Protocol}

A force-displacement hybrid control loading protocol was applied to attain the strength and stiffness degradation according to JGJ/T 101-2015. The loading protocol is shown in Figure 5. At the beginning of the test, the vertical load was gradually applied to the designed value to the specimen through the L-shaped loading beam from the two vertical actuators. Then, the lateral cyclic loading began with a force-controlled stage. The lateral load was cycled once starting with approximately $20 \%$ of the predicted cracking capacity until the first major diagonal crack was observed. The displacement at first major diagonal crack was defined as $\Delta$. Afterwards, the displacement-controlled loading stage was applied. The lateral load was cycled twice until the lateral capacity dropped to $85 \%$ of the peak strength according to JGJ/T 101-2015. The loading protocol in this study was used in previous experimental programs $[22,30]$. 


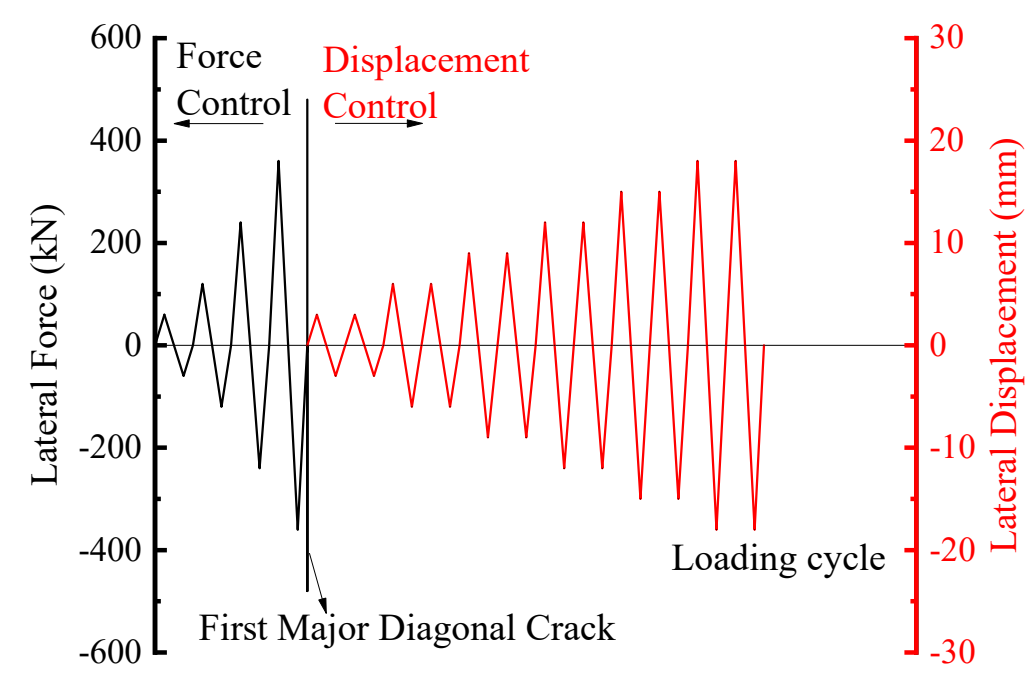

Figure 5. Loading procedure.

\section{Results and Discussion}

\subsection{Crack Pattern and Failure Mode}

Figure 6 shows the crack patterns and failure modes of the four tested walls. The drift ratio was computed as the horizontal displacement divided by the actual height of the wall $(2790 \mathrm{~mm})$. PCMW was a rectangular wall with a prefabricated construction technique. Several stepped mortar joint cracks were observed at both segments at the load of $420 \mathrm{kN}$ with a $0.09 \%$ drift loading cycle. No cracks were seen at the vertical joint. The first major diagonal crack was visible at $6 \mathrm{~mm}$ with a $0.21 \%$ drift loading cycle and extended to the right toe of the wall. A few stepped mortar joint cracks were seen over the lower five courses above the foundation at a distance about $600 \mathrm{~mm}$ from both wall ends. During the loading cycle at $12 \mathrm{~mm}$ with a $0.43 \%$ drift cycle, the wall reached its lateral capacity of $+624 \mathrm{kN}$ and $-675 \mathrm{kN}$ for both directions. As the test continued, progressive penetration of the diagonal cracks extended to the full height of the wall at $18 \mathrm{~mm}$ with a $0.64 \%$ drift loading cycle. The cracks were distributed on the entire wall. The major diagonal crack became wider and the mortar at the interaction of the bed and head joints expanded outwards, which led to a separation between mortar and units at $24 \mathrm{~mm}$ with a $0.86 \%$ drift loading cycle. The wall lost $8 \%$ of its lateral strength. During the loading cycle at $30 \mathrm{~mm}$ with a $1.07 \%$ drift top wall displacement, face shell spalling of units along the major diagonal crack occurred. Vertical cracks at the wall toes over the lower three courses above the foundation reinforced concrete beam widened and resulted in a face shell separation. Furthermore, damage in both sides of the segments was more severe than in the vertical joint with respect to the width and quantity of the diagonal cracks. The test ended with the strength decreasing to $74 \%$ of peak load.

PCMWT was a flanged wall with a prefabricated construction technique. A similar crack pattern was observed in both PCMWT and PCMW. PCMWT showed elastic behavior until the loading reached $660 \mathrm{kN}$. The first slight cracks were observed in the positive loading direction at a lateral load of $+720 \mathrm{kN}$ and a top lateral load of $3.64 \mathrm{~mm}$ with a $0.13 \%$ drift. The first visible cracks were composed of a combination of several stepped cracks along the mortar bed joints and head joints as well as diagonal cracks penetrating through the masonry units at the lower half of the wall. As the imposed lateral displacement increased, the first major diagonal crack appeared and simultaneously extended to the full height of the wall at the $4 \mathrm{~mm}$ with a $0.14 \%$ drift loading cycle. With further loading, the wall reached its lateral capacity of $906 \mathrm{kN}$ for the positive direction at $8 \mathrm{~mm}$ with a $0.29 \%$ drift loading cycle. During this loading circle, horizontal mortar cracks were observed at webs of the flanges up to the fifth course. The wall reached an ultimate resistance of $-857 \mathrm{kN}$ for the negative direction at $12 \mathrm{~mm}$ with a $0.43 \%$ drift loading cycle. Diagonal cracks parallel to the major ones in both directions were observed and constantly extended 
to the ends of the walls at approximately 45 degrees. Vertical cracks in both flanged end zones extending to the fourth course were also seen. During the loading cycle at $20 \mathrm{~mm}$ with a $0.71 \%$ drift top wall displacement, extensive diagonal cracks extended into wall toes and distributed on the entire wall. The crack width continued to increase. The wall lost about $18 \%$ of its capacity. The major diagonal crack gradually became distinct with a width of $6 \mathrm{~mm}$ at $24 \mathrm{~mm}$ with a $0.86 \%$ drift loading circle. Spalling of the face shells along the major diagonal crack at both segments occurred as the crack continued to widen. At the end of the test and at $32 \mathrm{~mm}$ with $1.14 \%$ drift loading cycle, vertical cracks at the flanged end zone and the major diagonal crack became wider. A significant face shell spalling in these regions led to a loss of $38 \%$ of the wall capacity.

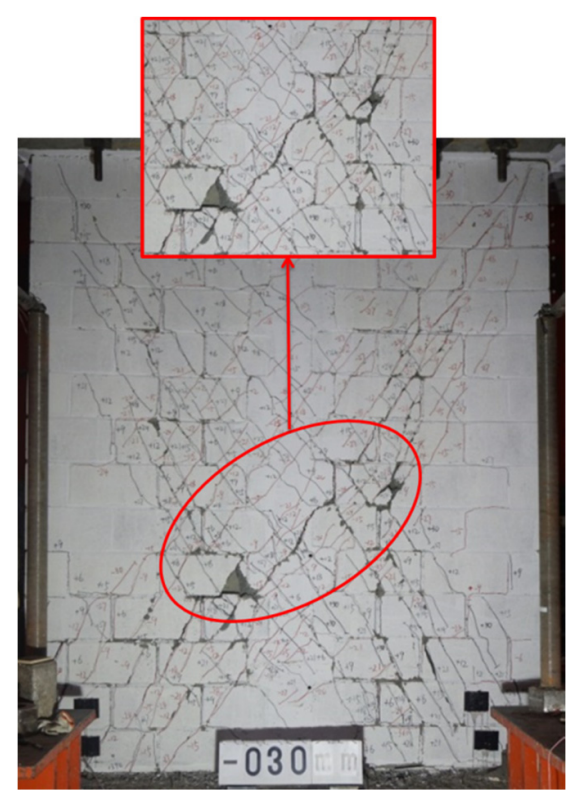

(a)

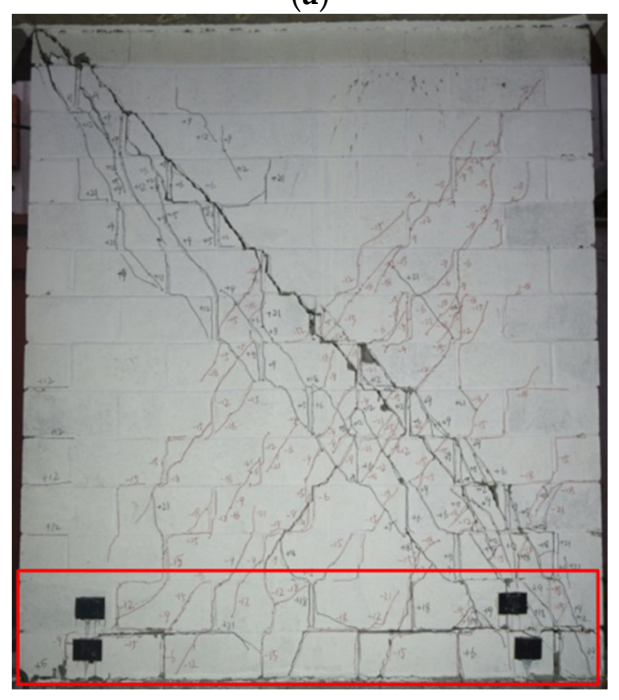

(c)

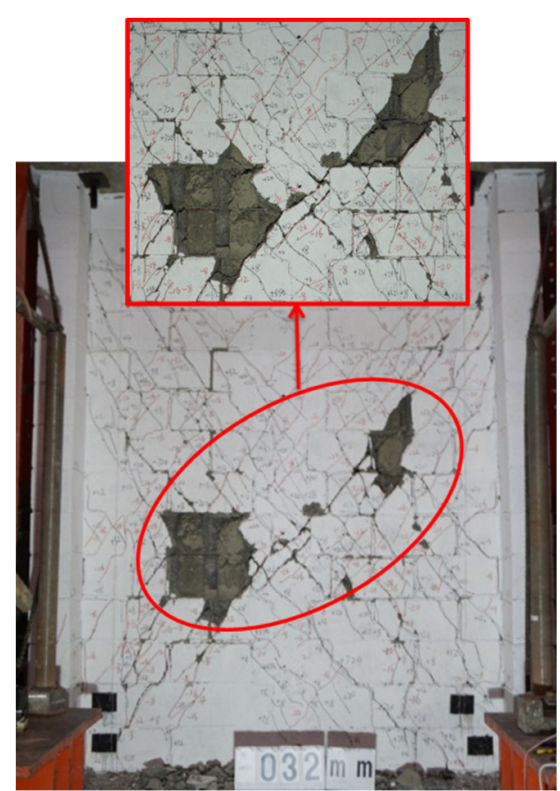

(b)

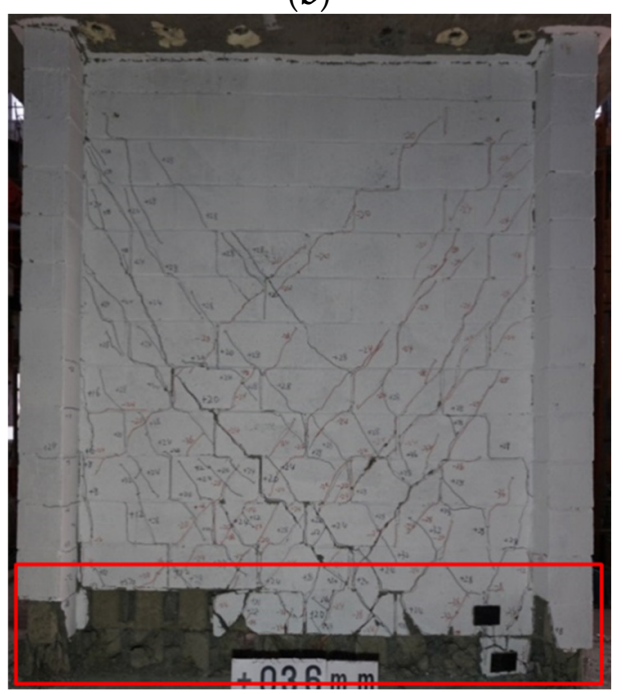

(d)

Figure 6. Failure modes of the specimens: (a) PCMW, (b) PCMWT, (c) CMW, and (d) CMWT.

CMW was a rectangular wall with a traditional construction technique. Compared to the prefabricated walls, CMW showed a different crack propagation and distribution. The first major diagonal crack was observed in the positive loading direction, which extended to the entire height of the wall at $6 \mathrm{~mm}$ with a $0.21 \%$ drift loading cycle. During the loading cycle at $9 \mathrm{~mm}$ with a $0.32 \%$ drift top wall displacement, the wall reached its lateral capacity 
of $+675 \mathrm{kN}$ and $-628 \mathrm{kN}$ for both directions. Diagonal cracks in the negative directions extended to the entire height of the wall. Horizontal cracks were observed at both wall ends at the lower six courses above the foundation with a length of $200 \mathrm{~mm}$ at $12 \mathrm{~mm}$ with a $0.43 \%$ drift loading cycle. During the $18 \mathrm{~mm}$ with $0.64 \%$ drift loading cycle, diagonal cracks became wider. An $8 \mathrm{~mm}$ wide major diagonal crack led to a face shell separation in this region. Most of the damage was limited to the major diagonal cracks and the first course of the wall. Less damage was observed at the middle top of the wall. At the end of the test at $32 \mathrm{~mm}$ with a $1.14 \%$ drift loading cycle, the strength dropped to $70 \%$ of the peak load.

CMWT was a flanged wall with a traditional construction technique. During the loading cycle at $8 \mathrm{~mm}$ with a $0.29 \% \mathrm{drift}$, stepped mortar cracks at the ends of wall web were observed over the lower four courses above the foundation. The horizontal cracks at the webs of the flanges were also seen. Vertical cracks at the flanged end zones extending to the second course were also observed. Diagonal cracks were observed in the middle third of the wall height in the positive loading direction at $20 \mathrm{~mm}$ with a $0.71 \%$ drift loading cycle. The wall reached ultimate resistances of $+728 \mathrm{kN}$ and $-662 \mathrm{kN}$ for both directions at the loading cycle of $24 \mathrm{~mm}$ with a $0.86 \%$ drift top displacement. The first major diagonal crack extended from the wall toes to the top of the wall. The diagonal cracks in the positive loading direction became wider. Extensive diagonal cracks in both directions were observed during the loading cycle at $32 \mathrm{~mm}$ with a $1.14 \%$ drift. The damage was mainly distributed in the lower half height of the wall. The diagonal crack was incrementally widened, which led to a significant face shell spalling at the lower two courses of the wall. The vertical reinforcement buckled in this region when removing the crumbling grout columns. The wall lost about $25 \%$ of its resistance.

All the walls presented diagonal shear failure. Two main types of diagonal cracking were observed. The first type included stepped cracks along the bed joints and vertical joints. This can be explained that the principal stress exceeded the bond strength between the units and mortar where the material was the weakest in the specimen. The second type included diagonal cracks crossing the units and mortars. This indicated the principal stress exceeded the tensile strength of the material.

In addition, the diagonal cracks parallel to each other occurred at approximately $45^{\circ}$ relative to the floor, which is perpendicular to the angle of principal stress. At the post-peak stage, the face shell spalling was observed because of the increasing width of the cracks. The first sets of visible diagonal cracks in the prefabricated walls (PCMW and PCMWT) were located at both segments at the wall ends. In addition, compared to both segments, the vertical joint in the middle of the specimen had less damage. This is because the material strength of grout in the vertical joint is higher than the masonry strength, despite the shear stress being highest in the middle of the wall.

Furthermore, the cracks in the cast-in-place specimens (CMW and CMWT) were mainly distributed in the lower half of the walls. This is because the connection methods of the vertical reinforcements were continuous on the top and overlapped on the bottom of the specimens, respectively. The grout in the first course of the wall peeled off because of the lack of protection from unit face shells where the vertical rebar overlapped. It illustrated that the use of cleaning-hole units and overlapped reinforcement changed the crack distribution. However, the proposed prefabricated construction method solved the abovementioned problems and consequently attained a uniformly distributed cracking pattern.

\subsection{Force-Displacement Response}

Figure 7 shows the hysteretic behavior of the tested walls. The skeleton curves of the specimens are shown in Figure 8. PCMW, PCMWT, and CMWT displayed symmetric behavior during the test. However, CMW showed asymmetric curves at the post-peak stage. This was because the first major diagonal crack in the positive direction was earlier than that in the negative direction. The pinching effect in prefabricated walls was more 
obvious than it was in cast-in-place walls. All the walls displayed elastic behavior before the first major diagonal crack occurred. The hysteretic loop was narrow, which illustrates low energy dissipation capacity. As the imposed displacement increased, the loop enlarged rapidly, which also indicates a high level of energy dissipation at the post-peak phase.

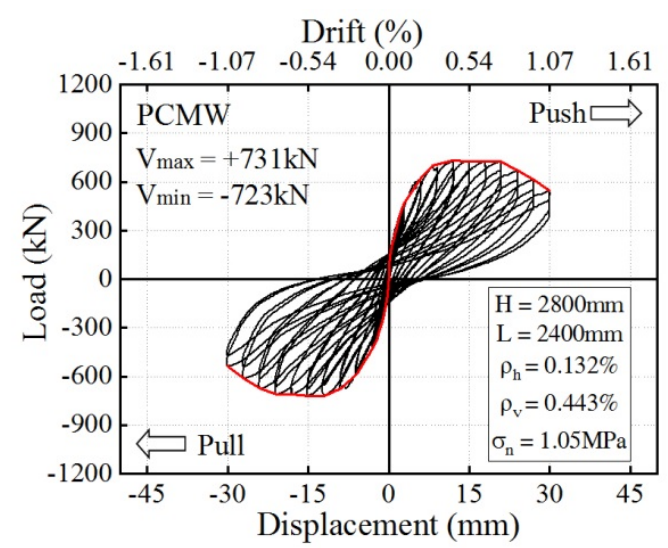

(a)

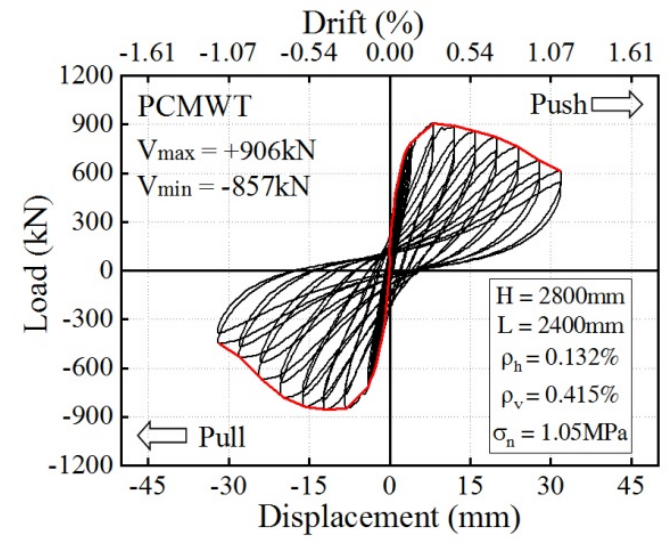

(c)

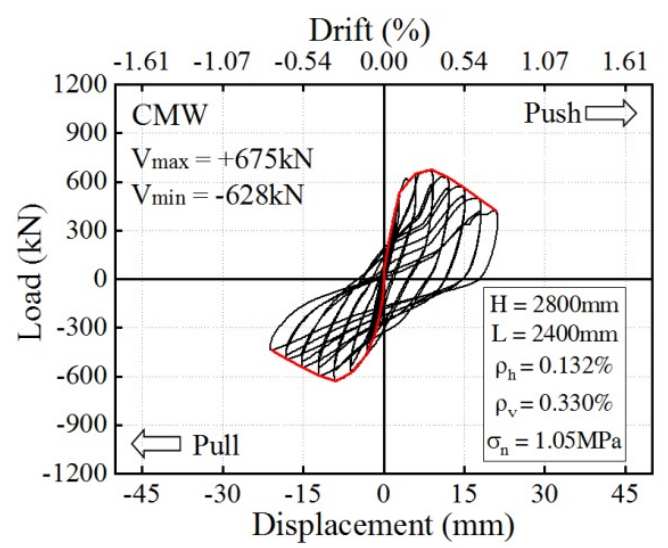

(b)

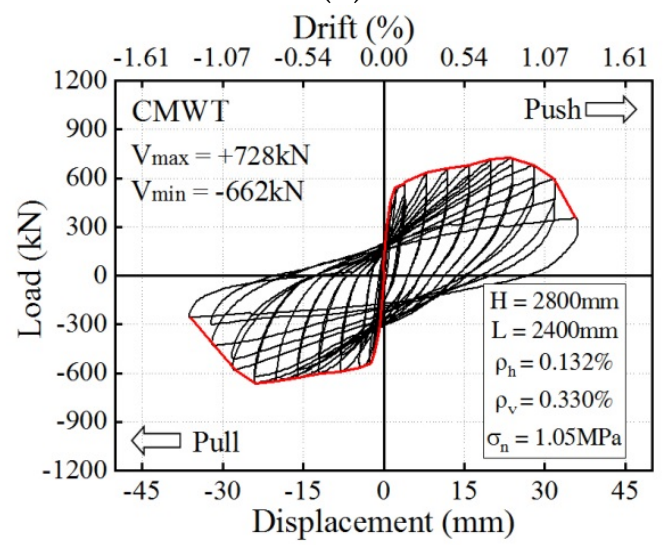

(d)

Figure 7. Hysteresis curves of the specimens: (a) PCMW, (b) CMW, (c) PCMWT, and (d) CMWT.

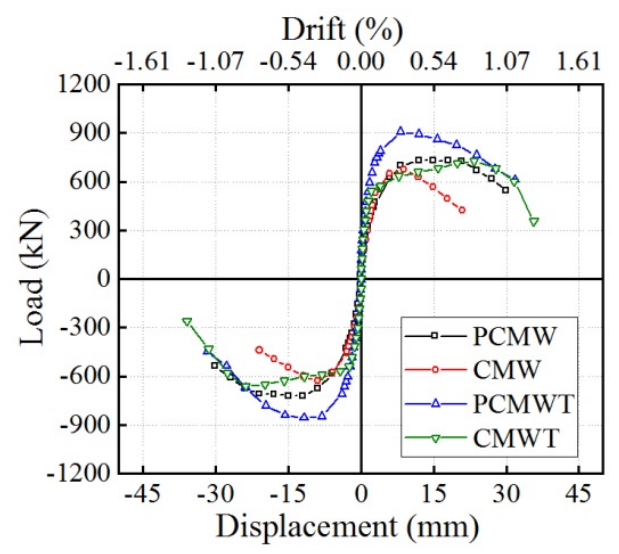

Figure 8. Skeleton curves of the test walls.

The bearing capacity of the prefabricated walls PCMW and PCMWT decreased slowly, which indicates a ductile failure process. However, the cast-in-place ones exhibited a rapid capacity degradation, which indicates a brittle failure mode.

All the tested walls had the same level of axial compressive stress and horizontal reinforcement ratio. The differences between the walls were mainly in the types of cross 
sections and construction methods. The lateral capacity of PCMWT and CMWT with a Tshaped section was $21 \%$ and $7 \%$ higher than that of the corresponding rectangular sections of PCMW and CMW, respectively. This illustrated that the flanges of the wall enhanced the bearing capacity in compression. However, the lateral resistance of the T-shaped walls dropped more rapidly than that of the rectangular section walls. This illustrated that increasing the compression area of the wall did not improve the post-peak strength or ductility of the wall. Regarding the construction method, the lateral capacity of PCMW and PCMWT was $12 \%$ and $27 \%$ higher than that of the corresponding cast-in-place walls, CMW and CMWT, respectively. This indicates that the vertical joint enhanced the shear capacity of the wall. The residual dropping mortars during the construction weakened the bond strength and friction at the interface of the walls and the bottom of the concrete beam. The continuous vertical reinforcement in PCMW and PCMWT performed better than that in CMWT and CMW where the vertical reinforcement was overlapped. The experiment results are summarized in Table 2 for a quantitative comparison of the specimen deformation characteristics at the stages of the first diagonal crack, peak load, and 15\% strength degradation.

Table 2. Test results and experimental displacement ductility.

\begin{tabular}{|c|c|c|c|c|c|c|c|c|c|}
\hline \multirow[b]{2}{*}{ Wall ID } & \multirow[b]{2}{*}{ Direction } & \multicolumn{2}{|c|}{ First Crack State } & \multicolumn{2}{|c|}{ Peak State } & \multicolumn{2}{|c|}{ Final State } & \multirow[b]{2}{*}{$\mu_{\exp }$} & \multirow{2}{*}{$\bar{\mu}_{\exp }$} \\
\hline & & $\begin{array}{c}\mathrm{V}_{\mathrm{e}} \\
(\mathbf{k N})\end{array}$ & $\begin{array}{c}\Delta_{\mathrm{e}} \\
(\mathrm{mm})\end{array}$ & $\begin{array}{c}\mathrm{V}_{\mathrm{u}} \\
(\mathbf{k N})\end{array}$ & $\begin{array}{c}\Delta_{\mathbf{u}} \\
(\mathrm{mm})\end{array}$ & $\begin{array}{l}\mathrm{V}_{0.85 \mathrm{u}} \\
(\mathbf{k N})\end{array}$ & $\begin{array}{l}\Delta_{0.85 \mathrm{u}} \\
(\mathrm{mm})\end{array}$ & & \\
\hline PCMW & $\begin{array}{l}(+) \\
(-)\end{array}$ & $\begin{array}{c}624 \\
-675\end{array}$ & $\begin{array}{c}5.9 \\
-8.9\end{array}$ & $\begin{array}{c}731 \\
-723\end{array}$ & $\begin{array}{c}11.9 \\
-12.0\end{array}$ & $\begin{array}{c}621 \\
-615\end{array}$ & $\begin{array}{c}26.7 \\
-26.7\end{array}$ & $\begin{array}{l}4.5 \\
3.0\end{array}$ & 3.8 \\
\hline CMW & $\begin{array}{l}(+) \\
(-)\end{array}$ & $\begin{array}{c}651 \\
-577\end{array}$ & $\begin{array}{c}5.9 \\
-5.9\end{array}$ & $\begin{array}{c}675 \\
-628\end{array}$ & $\begin{array}{c}8.9 \\
-9.0\end{array}$ & $\begin{array}{c}574 \\
-534\end{array}$ & $\begin{array}{c}14.5 \\
-15.7\end{array}$ & $\begin{array}{l}2.5 \\
2.7\end{array}$ & 2.6 \\
\hline PCMWT & $\begin{array}{l}(+) \\
(-)\end{array}$ & $\begin{array}{c}790 \\
-848\end{array}$ & $\begin{array}{c}4.0 \\
-8.0\end{array}$ & $\begin{array}{c}906 \\
-857\end{array}$ & $\begin{array}{c}8.1 \\
-11.8\end{array}$ & $\begin{array}{c}770 \\
-729\end{array}$ & $\begin{array}{c}23.3 \\
-21.7\end{array}$ & $\begin{array}{l}5.8 \\
2.7\end{array}$ & 4.3 \\
\hline CMWT & $\begin{array}{l}(+) \\
(-)\end{array}$ & $\begin{array}{c}660 \\
-601\end{array}$ & $\begin{array}{c}11.1 \\
-11.4\end{array}$ & $\begin{array}{c}728 \\
-662\end{array}$ & $\begin{array}{c}23.4 \\
-23.9\end{array}$ & $\begin{array}{c}619 \\
-563\end{array}$ & $\begin{array}{c}31.9 \\
-30.8\end{array}$ & $\begin{array}{l}2.9 \\
2.7\end{array}$ & 2.8 \\
\hline
\end{tabular}

\subsection{Displacement Ductility}

Displacement ductility is a key seismic parameter that reflects the inelastic deformation capacity of specimens without significant strength degradation in the post-yield phase. The methodology adopted in this study was based on an equal-energy system proposed by Tomaževič [31]. Figure 9 describes the idealized elastic-plastic envelop and experimental curve. The parameters used in the idealized elastic-plastic envelop and equivalent displacement ductility are summarized in Table 3 . The idealized lateral capacity can be computed by Equation (1).

$$
\mathrm{V}_{\text {ideal }}=\mathrm{K}_{\mathrm{e}} \times\left(\Delta_{0.85 \mathrm{u}}-\sqrt{\Delta_{0.85 \mathrm{u}^{2}}-\frac{2 \mathrm{~A}_{\mathrm{env}}}{\mathrm{K}_{\mathrm{e}}}}\right)
$$

where $\Delta_{0.85 \mathrm{u}}$ is the lateral strength dropped to $85 \%$ of the peak resistance; $\mathrm{A}_{\text {nev }}$ is the area under the experimental resistance envelope.

Table 2 shows the experimental displacement ductility $\left(\mu_{\exp }\right)$, which is defined as the ratio between the lateral displacements when the lateral capacity dropped to $85 \%$ of the maximum load and when the first major diagonal crack occurred. The experimental displacement ductility ranged from 2.6 to 4.3 , and the equivalent displacement ductility $\left(\mu_{\text {ideal }}\right)$ ranged from 2.3 to 3.8 . It is obvious that the calculated equivalent displacement ductility was about $12 \%$ lower than the experiment displacement ductility. However, the ductility results from two methods displayed a consistent trend regarding the studied parameters. 


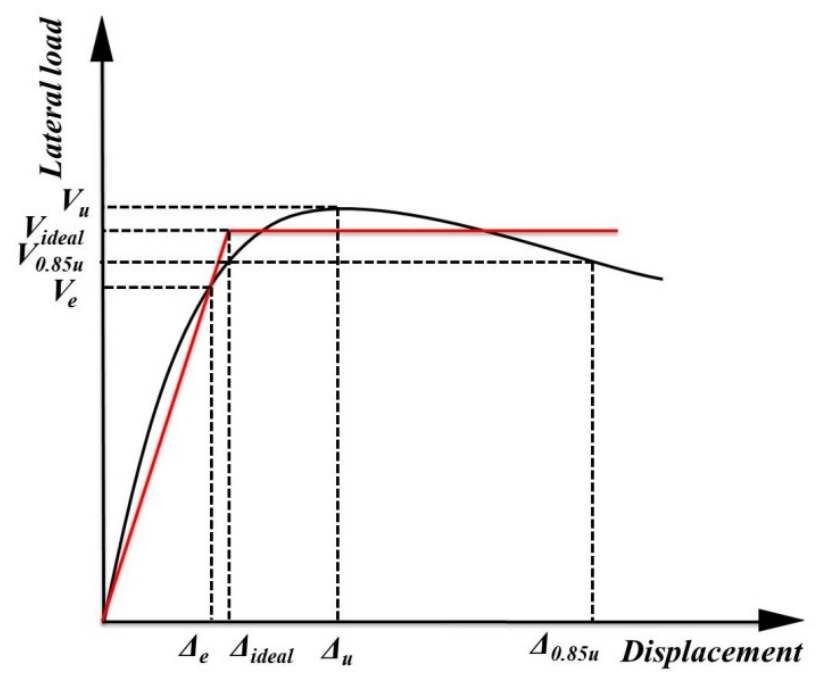

Figure 9. Idealized equivalent elastic-plastic system.

Table 3. Idealized elastic-plastic envelope parameters and equivalent displacement ductility.

\begin{tabular}{|c|c|c|c|c|c|c|c|c|}
\hline $\begin{array}{l}\text { Wall } \\
\text { ID }\end{array}$ & Direction & $\begin{array}{c}K_{\mathrm{e}} \\
(\mathrm{kN} / \mathrm{mm})\end{array}$ & $\begin{array}{c}\text { Aenv }_{\text {env }} \\
(\mathrm{kN} \bullet \mathrm{mm})\end{array}$ & $\begin{array}{l}\Delta_{0.85 \mathrm{u}} \\
(\mathrm{mm})\end{array}$ & $\begin{array}{l}\mathrm{V}_{\text {ideal }} \\
(\mathrm{kN})\end{array}$ & $\begin{array}{l}\Delta_{\text {ideal }} \\
(\mathrm{mm})\end{array}$ & $\mu_{\text {ideal }}$ & $\bar{\mu}_{\text {ideal }}$ \\
\hline \multirow{2}{*}{ PCMW } & $(+)$ & 105.1 & 17,135 & 26.7 & 739 & 7.0 & 3.8 & \multirow{2}{*}{3.2} \\
\hline & $(-)$ & 75.7 & 16,623 & -26.7 & -769 & 10.2 & 2.6 & \\
\hline \multirow{2}{*}{ CMW } & $(+)$ & 111.0 & 8171 & 14.5 & 728 & 6.6 & 2.2 & \multirow{2}{*}{2.3} \\
\hline & $(-)$ & 97.4 & 8201 & -15.7 & -668 & 6.9 & 2.3 & \\
\hline \multirow{2}{*}{ PCMWT } & $(+)$ & 199.6 & 18,751 & 23.3 & 890 & 4.5 & 5.2 & \multirow{2}{*}{3.8} \\
\hline & $(-)$ & 105.5 & 16,270 & -21.7 & 945 & 9.0 & -2.4 & \\
\hline \multirow{2}{*}{ CMWT } & $(+)$ & 56.3 & 19,836 & 31.9 & 855 & 10.6 & 2.9 & \multirow[b]{2}{*}{2.7} \\
\hline & $(-)$ & 51.2 & 16,646 & -30.8 & 834 & 11.2 & -2.5 & \\
\hline
\end{tabular}

The displacement ductility of prefabricated walls was $41 \%$ and $39 \%$ higher than that of cast-in-place walls regarding flanged and rectangular cross sections, respectively. This implies that the existence of vertical joints and continuous vertical reinforcement connections enhanced the deformability of the walls in the post-peak phase. This is also evidenced by the observation of uniformly distributed crack patterns in the prefabricated walls (PCMW and PCMWT). Nevertheless, the cracks of the cast-in-place walls were distributed mainly at the bottom of the wall. With respect to the cross section, the displacement ductility of the flanged walls was 19\% and 17\% higher than that of rectangular walls for prefabricated and traditional construction techniques, respectively. The reason for the higher displacement ductility was the configuration of the flanges, which lead to a larger compression area and enabled maintaining the lateral resistance at high drift levels. This was also found in a previous study [26].

\subsection{Stiffness Degradation}

The secant stiffness at each load cycle can be calculated by Equation (2):

$$
\mathrm{K}_{\mathrm{si}}=\frac{\mathrm{V}_{\max , \mathrm{i}}-\mathrm{V}_{\min , \mathrm{i}}}{\delta_{\max , \mathrm{i}}-\delta_{\min , \mathrm{i}}}
$$

where $V_{\max , i}$ and $V_{\min , i}$ are the maximum loads at cycle $i ; \delta_{\max , i}$ and $\delta_{\min , i}$ are the lateral displacements corresponding to $\mathrm{V}_{\max , \mathrm{i}}$ and $\mathrm{V}_{\min , \mathrm{i}}$. The initial stiffness of wall $\mathrm{K}_{\mathrm{e}}$ was computed at the lateral load corresponding to $20 \%$ of the predicted cracking strength for masonry walls, where it is considered that the wall still maintains elastic behavior. 
PCMWT and CMWT had an initial stiffness $\left(\mathrm{K}_{0}\right)$ of 630.7 and $630.6 \mathrm{kN} / \mathrm{mm}$, respectively. PCMW and CMW had an initial stiffness fo 388.8 and $386.8 \mathrm{kN} / \mathrm{mm}$, respectively. This indicated that a T-shaped cross section increased the initial stiffness of the specimens by $62 \%$ compared to that of rectangular walls. However, the construction method had no influence on that. This is because the initial stiffness is related to the cross-sectional inertia moment.

Figure 10 shows the normalized stiffness degradation with respect to $\mathrm{K}_{0}$. In general, the secant stiffness decreased sharply at low values of drift and then dropped slowly at high values of drift. The secant stiffness dropped to $30 \%$ of the initial stiffness at $0.21 \%$ drift when the first major diagonal crack was observed. At the ultimate loading, the stiffness was approximately $5 \%$ of the initial stiffness. The stiffness of specimens PCMWT and CMWT with flanges decreased rapidly compared to that of the cast-in-place walls until the first major diagonal crack occurred. This illustrated that the flange of the wall increased the initial stiffness but lead to a rapid stiffness degradation.

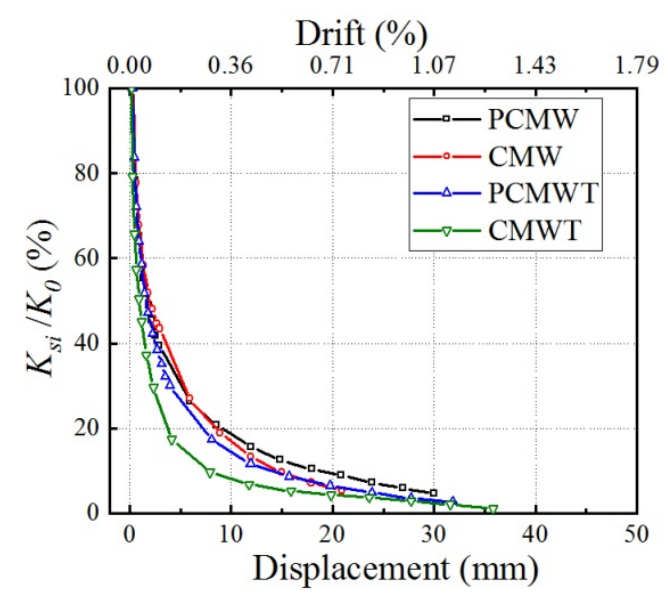

Figure 10. Normalized stiffness degradation of specimens.

\subsection{Energy Dissipation}

Energy dissipation is an important index for evaluating the seismic performance of a structural member. A high energy dissipation capacity can reduce the seismic response and demands. The energy dissipation was estimated by calculating the enclosed area of the hysteretic loops. Figure 11 shows the single circle and cumulative energy dissipation versus lateral displacement. The capacity of energy dissipation for all test walls was basically same until the lateral displacement reached $3 \mathrm{~mm}(0.11 \%$ drift). The slope had an obvious increase when the first major diagonal crack occurred, which implied the horizontal reinforcement worked to dissipate energy. Regarding the construction method, the cast-in-place walls had higher energy dissipation capacity than did the prefabricated ones at the same lateral drift. This indicated that the energy dissipation was related to the location and direction of the diagonal cracks. A larger compression zone in the cast-in-place walls contributed to better energy dissipation than in the prefabricated ones. With respect to cross section, the T-shaped cross section improved the energy dissipation capacity compared to that of the rectangular section. This is because the boundary flange increased the compression area of the wall, which improved the lateral capacity. Therefore, walls with a T-shaped section had a higher lateral capacity at the same lateral displacement. 


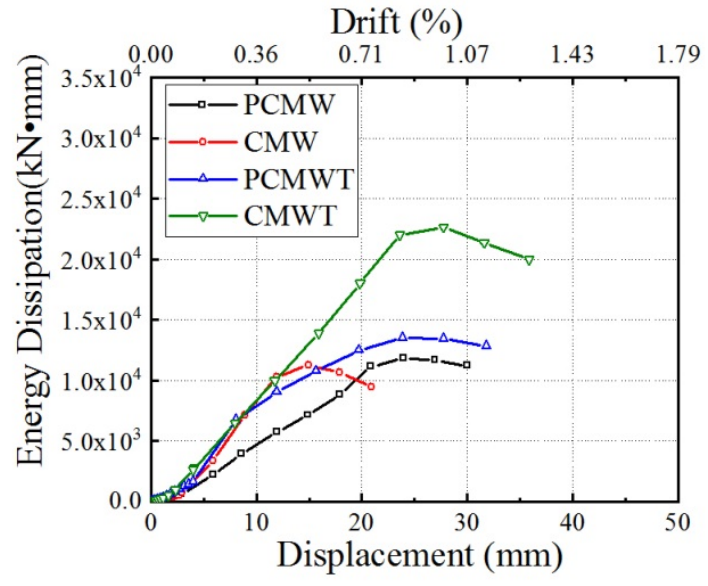

(a)

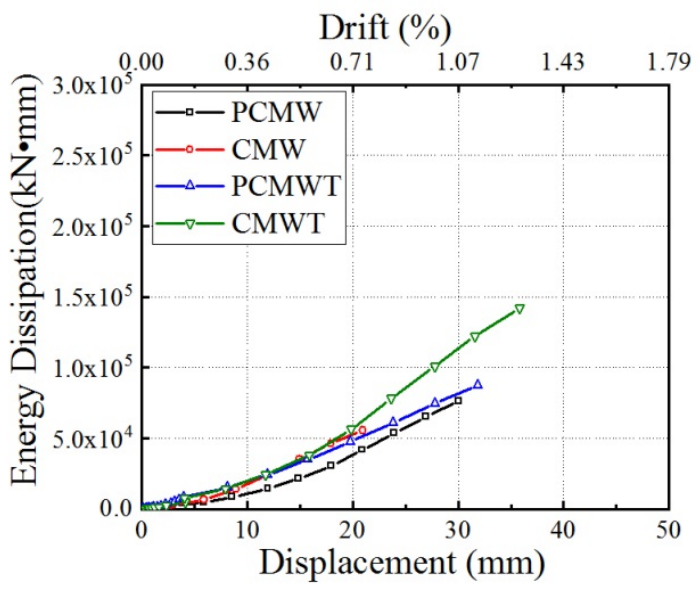

(b)

Figure 11. Energy dissipation: (a) single cycle and (b) cumulative.

\subsection{Equivalent Viscous Damping}

As shown in Figure 12, the equivalent damping ratio can be computed by Equation (3):

$$
\xi_{\mathrm{eq}}=\frac{1}{2 \pi} \times \frac{\mathrm{S}_{(\mathrm{ABC}+\mathrm{CDA})}}{\mathrm{S}_{(\mathrm{OBE}+\mathrm{ODF})}}
$$

where $\mathrm{S}_{(\mathrm{ABC}+\mathrm{CDA})}$ denotes the area enclosed by the hysteretic loop and $\mathrm{S}_{(\mathrm{OBE}+\mathrm{ODF})}$ denotes the area of triangles that represents the rigid, perfectly plastic curve.

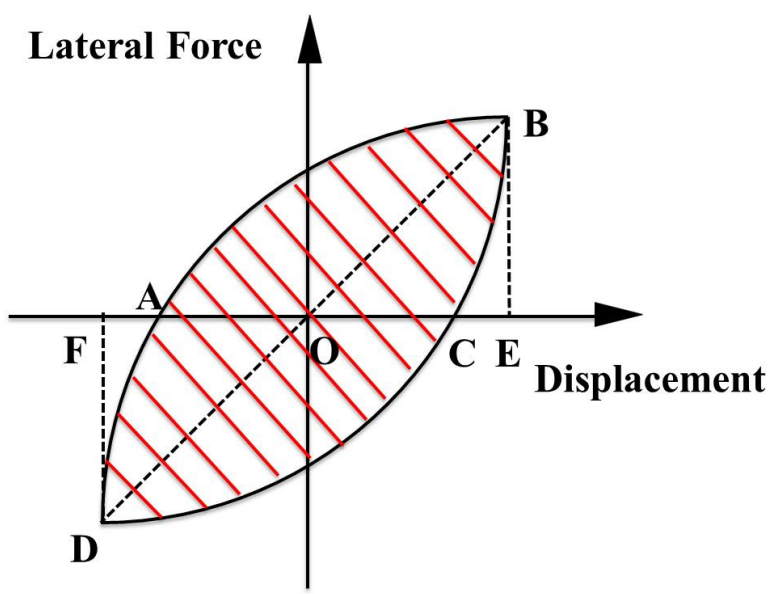

Figure 12. Schematic of the load-deformation hysteresis curve.

The equivalent damping ratio versus lateral drift is plotted in Figure 13. At the beginning of the test, the equivalent damping ratio was high, ranging from 0.26 to 0.45 . Then, the equivalent damping ratio dropped rapidly to approximately 0.10 at the lateral displacement of $3 \mathrm{~mm}$. As the lateral displacement increased, the equivalent damping ratio increased to a steady value of 0.26 and 0.13 for prefabricated walls and cast-in-place walls, respectively. However, the equivalent viscous damping of reinforced concrete masonry structures was assumed, ranging from 0.07 to 0.10 . This indicated that the structures with RMSWs can provide a high level of damping and, hence, reduce the seismic demand. Regarding to the construction method, the equivalent damping ratios of cast-in-place walls were higher than those of prefabricated walls, which was also found in previous literature [21]. 


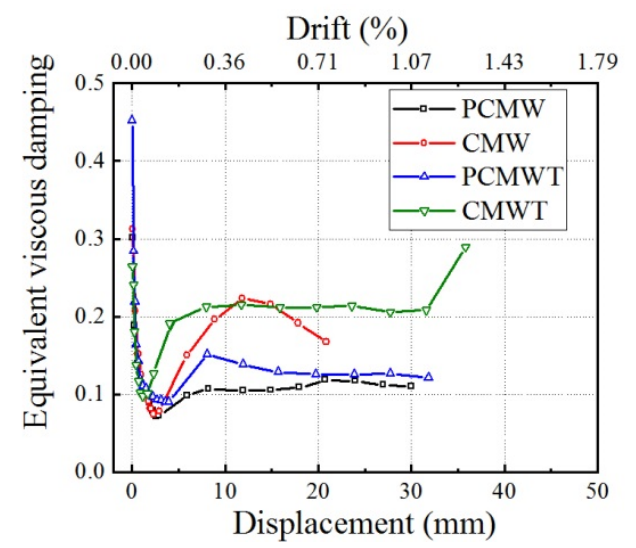

Figure 13. Equivalent viscous damping of the tested walls.

\section{Conclusions}

This paper presents a comparative study on the in-plane seismic behavior of four single-story RMSWs under reversed cyclic loading. The effects of construction method and cross section on the seismic performance were evaluated according to displacement ductility, stiffness degradation, energy dissipation, and equivalent viscous damping. The following conclusions can be drawn:

(1) All the walls presented diagonal shear failure. The stepped cracks along the bed joints and vertical joints and diagonal crack crossing the units and mortars were observed. The first sets of visible diagonal cracks in the prefabricated walls were located at both segments at the wall ends. Furthermore, the cracks in the cast-in-place specimens were mainly distributed in the lower half of the walls. The grout in the first course of the wall peeled off because of the lack of protection from unit face shells where the vertical rebar overlapped. This illustrated that the use of cleaning-hole units and overlapped reinforcement changed the crack distribution.

(2) All the test specimens displayed symmetric behavior until the peak load. The lateral capacity of PCMWT and CMWT with a T-shaped section was $21 \%$ and $7 \%$ higher than that of the corresponding rectangular sections of PCMW and CMW, respectively. Regarding the construction method, the lateral capacity of PCMW and PCMWT was $12 \%$ and $27 \%$ higher than that of the corresponding cast-in-place walls, CMW and CMWT, respectively.

(3) The equivalent displacement ductility varied between 2.3 and 3.8, which is related to the studied parameters of construction method and cross section. The displacement ductility of prefabricated walls was $41 \%$ and $39 \%$ higher than that of the cast-in-place walls regarding flanged and rectangular cross sections, respectively. Furthermore, the displacement ductility of the flanged walls was 19\% and 17\% higher than that of rectangular walls for prefabricated and traditional construction techniques, respectively.

(4) The initial stiffness of the test walls in this study was predominantly influenced by the cross section. The T-shaped cross section increased the initial stiffness of the specimens by $62 \%$ compared to that of rectangular walls. The secant stiffness decreased sharply at low values of drift and then dropped slowly at high values of drift. Additionally, the stiffness of specimens with flanges decreased more rapidly than did that of cast-in-place walls until the first major diagonal crack occurred.

(5) The slope had an obvious increase when the first major diagonal crack occurred. The cast-in-place walls had higher energy dissipation capacity than did the prefabricated ones at the same lateral drift. The T-shaped cross section improved the energy dissipation capacity compared to that of the rectangular section. Then, the equivalent damping ratio dropped rapidly to approximately 0.10 and finally remained stable at a value of 0.13 and 0.26 for prefabricated and cast-in-place walls, respectively. 
Author Contributions: Formal analysis, Z.Z.; methodology, Z.Z.; writing—original draft preparation, Z.Z.; writing-review and editing, F.W. All authors have read and agreed to the published version of the manuscript.

Funding: This research received no external funding.

Acknowledgments: The present work was conducted with the financial support of the National Key R\&D Plan-China (Grant No. 2016YFC0701502-3).

Conflicts of Interest: The authors declare no conflict of interest.

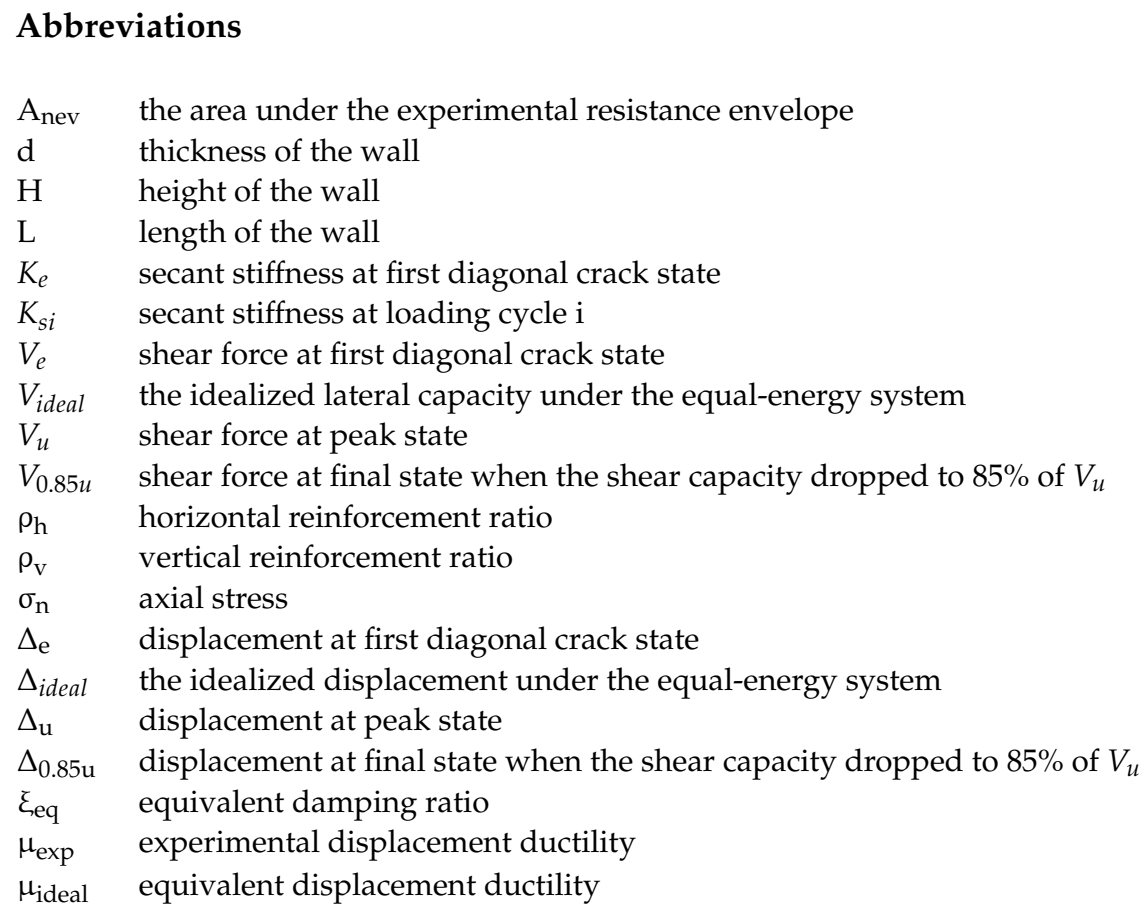

\section{References}

1. Wang, F.L.; Zhang, X.C.; Zhu, F. Research progress and low-carbon property of reinforced concrete block masonry structures in China. In Proceedings of the 16th International Brick and Block Masonry Conference, Padova, Italy, 26-30 June 2016; Taylor \& Francis Group: London, UK, 2016.

2. Corrêa, M.R. The evolution of the design and construction of masonry buildings in Brazil. Gestão Tecnol. Proj. 2012, 7, 3-11. [CrossRef]

3. El-Dakhakhni, W.; Ashour, A. Seismic Response of Reinforced-Concrete Masonry Shear-Wall Components and Systems: State of the Art. J. Struct. Eng. 2017, 143, 03117001. [CrossRef]

4. Shing, P.B.; Noland, J.L.; Klamerus, E.; Spaeh, H. Inelastic behavior of concrete masonry shear walls. J. Struct. Eng. 1989, 115, 2204-2225. [CrossRef]

5. Shing, P.B.; Schuller, M.; Hoskere, V.S. In-Plane Resistance of Reinforced Masonry Shear Walls. J. Struct. Eng. 1990, 116, 619-640. [CrossRef]

6. Shedid, M.T.; Drysdale, R.G.; El-Dakhakhni, W.W. Behavior of Fully Grouted Reinforced Concrete Masonry Shear Walls Failing in Flexure: Experimental Results. J. Struct. Eng. 2008, 134, 1754-1767. [CrossRef]

7. Shedid, M.T.; El-Dakhakhni, W.W.; Drysdale, R.G. Behavior of fully grouted reinforced concrete masonry shear walls failing in flexure: Analysis. Eng. Struct. 2009, 31, 2032-2044. [CrossRef]

8. Priestley, M.J.N. Seismic design of concrete masonry shear walls. Amer. Concr. Inst. Struct. J. 1986, 83, 58-68. [CrossRef]

9. Ibrahim, K.S.; Suter, G.T. Ductility of concrete masonry shear walls subjected to cyclic loading. In Proceedings of the 8th North American Masonry Conference, Austin, TX, USA, 6-9 June 1999; The Masonry Society: Longmont, CO, USA, 1999.

10. Zou, X.; Feng, P.; Wang, J.; Wu, Y.; Fan, Y. FRP stay-in-place form and shear key connection for FRP-concrete hybrid beams/decks. Compos. Struct. 2018, 192, 489-499. [CrossRef]

11. Funari, M.F.; Greco, F.; Lonetti, P. A coupled ALE-Cohesive formulation for layered structural systems. Procedia Struct. Integr. 2017, 3, 362-369. [CrossRef]

12. El-Dakhakhni, W.W.; Banting, B.R.; Miller, S.C. Seismic Performance Parameter Quantification of Shear-Critical Reinforced Concrete Masonry Squat Walls. J. Struct. Eng. 2013, 139, 957-973. [CrossRef] 
13. Eldin, H.M.S.; Galal, K. In-Plane Seismic Performance of Fully Grouted Reinforced Masonry Shear Walls. J. Struct. Eng. 2017, 143, 04017054. [CrossRef]

14. Eldin, H.M.S.; Ashour, A.; Galal, K. Seismic performance parameters of fully grouted reinforced masonry squat shear walls. Eng. Struct. 2019, 187, 518-527. [CrossRef]

15. ElDin, H.M.S.; Aly, N.; Galal, K. In-plane shear strength equation for fully grouted reinforced masonry shear walls. Eng. Struct. 2019, 190, 319-332. [CrossRef]

16. Masoud, S.; Ehsan, A.; Mohammad, M.K. Micromechanical modeling of mortar joints and brick-mortar interfaces in masonry Structures: A review of recent developments. Structures 2020, 23, 831-844.

17. Aguilar, V.; Sandoval, C.; Adam, J.M.; Garzón-Roca, J.; Valdebenito, G. Prediction of the shear strength of reinforced masonry walls using a large experimental database and artificial neural networks. Struct. Infrastruct. Eng. 2016, 12, 1663-1676. [CrossRef]

18. Hung, J.; Cruz, C.; Sandoval, C.; Banting, B. Analysis of partially grouted masonry shear walls using artificial neural networks. In Proceedings of the 10th International Masonry Conference, Milan, Italy, 9-11 July 2018.

19. Vidal, V.A. Estimation of Shear Strength of Reinforced Masonry Walls. Comparative Study and Use of Artificial Neural Networks PhD Thesis, Austral University of Chile, Valdivia, Chile, 2013.

20. Xu, W.; Yang, X.; Wang, F.; Chi, B. Experimental and numerical study on the seismic performance of prefabricated reinforced masonry shear walls. Appl. Sci. 2018, 8, 1856. [CrossRef]

21. Xu, W.; Yang, X.; Wang, F.L. Experimental investigation on the seismic behavior of newly-developed precast reinforced concrete block masonry shear walls. Appl. Sci. 2018, 8, 1071. [CrossRef]

22. Zhang, Z.; Wang, F.; Chi, B. Seismic performance of shear-critical prefabricated reinforced masonry shear walls with innovative vertical joint connections. Eng. Struct. 2020, 219, 110958. [CrossRef]

23. Robazza, B.; Yang, T.; Brzev, S.; Elwood, K.; Anderson, D.; McEwen, W. Response of slender reinforced masonry shear walls with flanged boundary elements under in-plane lateral loading: An experimental study. Eng. Struct. 2019, 190, 389-409. [CrossRef]

24. Shedid, M.T.; El-Dakhakhni, W.W.; Drysdale, R.G. Characteristics of Rectangular, Flanged, and End-Confined Reinforced Concrete Masonry Shear Walls for Seismic Design. J. Struct. Eng. 2010, 136, 1471-1482. [CrossRef]

25. Shedid, M.T.; El-Dakhakhni, W.W.; Drysdale, R.G. Alternative Strategies to Enhance the Seismic Performance of Reinforced Concrete-Block Shear Wall Systems. J. Struct. Eng. 2010, 136, 676-689. [CrossRef]

26. El-Azizy, O.A.; Shedid, M.T.; El-Dakhakhni, W.W.; Drysdale, R.G. Experimental evaluation of the seismic performance of reinforced concrete structural walls with different end configurations. Eng. Struct. 2015, 101, 246-263. [CrossRef]

27. Standardization Administration of China. GB 50003-2011: Code for Design of Masonry Structure; Standardization Administration of China: Beijing, China. (In Chinese)

28. Standardization Administration of China. GB 50011-2010: Code for Seismic Design of Buildings; Standardization Administration of China: Beijing, China, 2010. (In Chinese)

29. Standardization Administration of China. JC861-2008: Grout for Concret Unit Masonry; Standardization Administration of China: Beijing, China, 2008. (In Chinese)

30. Chi, B.; Yang, X.; Wang, F.; Zhang, Z.; Quan, Y. Experimental investigation of effect of section configuration on seismic performance of an innovative integrated concrete masonry wall system. Eng. Struct. 2020, 206, 110163. [CrossRef]

31. Tomaževič, M. Earthquake-Resistant Design of Masonry Buildings; Imperial College PR: London, UK, 1999. 